\title{
Dendroecological reconstructions of forest disturbance history using time-series analysis with intervention detection
}

\author{
Daniel L. Druckenbrod
}

\begin{abstract}
The detection of release events in the annual growth increments of trees has become a central and widely applied method for reconstructing the disturbance history of forests. While numerous approaches have been developed for identifying release events, the preponderance of these methods relies on running means that compare the percent change in growth rates. These methods do not explicitly account for the autocorrelation present within tree-ring width measurements and may introduce spurious events. This paper utilizes autoregressive integrated moving-average (ARIMA) processes to model tree-ring time series and incorporates intervention detection to identify pulse and step outliers as well as changes in trends indicative of a deterministic exogenous influence on past growth. This approach is evaluated by applying it to three chronologies from the Forest Responses to Anthropogenic Stress (FORAST) project that were impacted by prior disturbance events. The examples include a hemlock (Tsuga canadensis (L.) Carrière) chronology from New Hampshire, a white pine (Pinus strobus L.) chronology from Pennsylvania, and an American beech (Fagus grandifolia Ehrh.) chronology from Virginia. All three chronologies exhibit a clustering of step, pulse, and trend interventions subsequent to a known or likely disturbance event. Time-series analysis offers an alternative approach for identifying prior forest disturbances via tree rings based on statistical methods applicable across species and disturbance regimes.
\end{abstract}

Résumé : La détection des épisodes de dégagement dans les accroissements annuels des arbres est devenue une méthode essentielle et largement appliquée pour reconstituer l'historique des perturbations dans les forêts. Alors que plusieurs approches ont été développées pour identifier les épisodes de dégagement, la prépondérance de ces méthodes repose sur des moyennes mobiles qui comparent le pourcentage de variation dans le taux de croissance. Ces méthodes ne tiennent pas explicitement compte de l'autocorrélation présente dans les mesures de largeur de cernes. Cet article utilise un processus autorégressif de moyennes mobiles intégrées pour modéliser les chronoséquences et incorpore (ARIMA) la détection des interventions pour identifier les impulsions et les observations aberrantes ainsi que les variations de tendance qui indiquent une influence déterministe exogène sur la croissance passée. Cette approche est évaluée pour trois courbes dendrochronologiques du projet « Forest Responses to Anthropogenic Stress » (FORAST) qui ont été affectées par des perturbations antérieures. Les exemples incluent des courbes dendrochronologiques de la pruche occidentale (Tsuga canadensis (L.) Carrière) provenant du New Hampshire, du pin blanc (Pinus strobus L.) provenant de la Pennsylvanie et du hêtre à grandes feuilles (Fagus grandifolia Ehrh.) provenant de la Virginie. Ces trois courbes montrent un regroupement de marches, d'impulsions et d'interventions subséquemment à un épisode connu ou probable de perturbation. L'analyse des courbes dendrochronologiques offre une approche alternative pour identifier les perturbations passées en forêt via les cernes annuels basée sur des méthodes statistiques applicables peu importe l'espèce et le régime de perturbation.

[Traduit par la Rédaction]

\section{Introduction}

Tree rings, when viewed as time series of annual increments, present a valuable, long-term record of tree growth across many forest environments (see Contributors to the International Tree-Ring Data Bank 2004). These records are capable of providing not only reconstructions of prior climates (Fritts 1976), but also ecological reconstructions of

Received 3 September 2004. Accepted 16 December 2004. Published on the NRC Research Press Web site at http://cjfr.nrc.ca on 7 May 2005.

D.L. Druckenbrod. Environmental Sciences Division, Oak Ridge National Laboratory, P.O. Box 2008, Oak Ridge, TN 37831-6036, USA (e-mail: druckenbrodd@ ornl.gov). forest history (Frelich 2002). In addition to estimates of tree age, tree rings may also reflect the impact of disturbance (sensu White and Pickett 1985) on the prior growth rate of surviving trees, which in turn provides historical insight into the proximal environment of a tree.

Early reconstructions of forest disturbance history showed an increase in the radial-growth rate following a disturbance event (Stephens 1956; Henry and Swan 1974; Oliver and Stephens 1977). Lorimer and Frelich (1989) proposed objective criteria for quantifying suppression and release growth patterns based on the mean percent change in growth rate. They defined a moderate release as an increase in the mean growth rate by $50 \%$ to $99 \%$ and a major release as an increase by at least $100 \%$. Similarly, a temporary release occurred for 10 to 15 years, while a sustained release lasted for 
more than 15 years. Nowacki and Abrams (1997) applied a modified form of these criteria in developing an iterative method to identify release events in oak (Quercus sp.) tree rings based on radial-growth averaging. Using thinning-response studies, they determined that a $25 \%$ increase between subsequent decadal intervals of mean radial-growth increments denoted a prior canopy disturbance. Their method and similar approaches have enabled reconstructions of disturbance history for a range of forest ecosystems (e.g., Abrams et al. 1999; Rozas 2003; Rentch et al. 2003) and have become the most commonly employed method of dendroecological reconstructions of disturbance history (Rubino and McCarthy 2004). Recently, Black and Abrams (2003) refined this method for three species by incorporating release criteria that are dependent on the magnitude of the prior mean growth rate. The release criteria utilize International Tree-Ring Data Bank data sets of each species to develop specific boundary lines that are a function of prior growth rates and express a tree species' potential to respond to a release. While the boundary-line approach is an innovative application of species biology, this paper presents an alternative approach to the detection of disturbance events in tree rings. Unlike these previous methods based on running means, this method utilizes time-series analysis with intervention detection to empirically identify outliers.

Time-series analysis has become a common approach for the modeling of dependent, sequential observations since the publication by Box and Jenkins (1970). Time-series analysis employs a variety of models, including autoregressive integrated moving-average (ARIMA) processes to describe the behavior of stochastic and dynamic systems (Box et al. 1994). These models may include autoregressive (AR), differencing, and moving-average parameters. While these methods enable forecasts of future values, they may also be applied to the estimation of transfer functions and interventions that characterize prior values in a series (Box et al. 1994). Intervention variables, which express a deterministic influence on a time series, may be either known a priori or suggested by the data via intervention detection procedures.

The use of intervention detection in time-series analysis has been advanced by several studies. Fox (1972) defined two types of outliers, or interventions, in time series: (1) additive outliers that affect the gross level of a particular observation and (2) innovational outliers that also affect subsequent observations. Box and Tiao (1975) formalized intervention analysis by presenting a suite of step and pulse responses that characterize the response of a time series to a known intervention in time. Building on the approach of intervention analysis, Chang (1982) developed intervention detection as a means to iteratively identify unknown pulse interventions in time series (see also Chang et al. 1988). Tsay (1988) further expanded intervention detection to encompass level shifts and variance changes as well as pulse outliers in a unified approach to the systematic identification of outliers in time series.

Dendroclimatologists have long recognized the presence of autocorrelation in time series of tree-ring widths. Fritts (1976) observed that climate variation affected not only the current year's growth of a tree, but also growth in subsequent years. Similarly, a tree may undergo physiological changes that influence its growth in subsequent years as it reacts to its environment (Fritts 1976). Early applications of time-series analysis to ring widths demonstrated that tree growth could be described typically by either AR or autoregressive moving-average (ARMA) processes (Meko 1981; Rose 1983; Cook 1985; Guiot 1986; Monserud 1986). These insights have placed time-series analysis as a central method in the reconstruction of prior climates from tree rings; however, this method has seldom been applied to the dendroecological reconstruction of forest disturbance history.

The Forest Responses to Anthropogenic Stress (FORAST) project collected radial-growth increments for 36 species within the eastern deciduous forests of North America (McLaughlin et al. 1988). The project compared radial-growth rates with a variety of environmental data, including forest-stand attributes, climate variables, and anthropogenic pollutants. The objectives were as follows: determine whether trends were present in the radial-growth rates, ascertain whether these trends were synchronous across species or sites, explore whether these trends could be ascribed to a causal environmental variable, and investigate the influence of local site conditions on any relationship. FORAST measured and compiled ring widths for approximately 7000 trees across 17 states in the United States. These trees were sampled across more than 100 sites with chronologies for each available species typically consisting of 15 trees with two cores extracted per tree.

Although FORAST initially examined trends across species and sites using the percent change in radial-growth rates, the project eventually became the first application of timeseries analysis with intervention detection to the ecological analysis of tree growth (see Downing and McLaughlin 1990). Employing time-series analysis with intervention detection and focusing on only the subset of red spruce (Picea rubens Sarg.) chronologies from the FORAST database, McLaughlin et al. (1987) observed a regional decline in radial-growth rates. Their research showed a substantial increase in the number of negative step interventions during the 1950s and 1960s in red spruce chronologies from both northern and southern sites. While FORAST did examine regional trends in other species using the percent growth change between two time periods, 27 of the 451 chronologies across all species were removed from any analysis, because they appeared to exhibit site-specific responses to prior disturbance (McLaughlin et al. 1988, see Appendix H). Three of these 27 chronologies have been selected as the focus for this study.

This paper revisits those three FORAST chronologies to investigate whether time-series analysis with intervention detection may also serve as an effective method for reconstructing site-specific forest disturbances. These chronologies are analyzed for pulse, step, and trend interventions. Changes in the numbers of interventions through time are compared with known or likely prior forest disturbances at each site to evaluate this approach across a range of environmental settings, disturbance regimes, and tree species.

\section{Methods}

Tree-ring width measurements were accessed using the FORAST database maintained online by Carbon Dioxide Information Analysis Center (McLaughlin et al. 1986). Three chronologies were selected from the FORAST database that encompass a range of species, geographical locations, and 
Table 1. Ranking of estimated stand disturbance history initially recorded by Forest Responses to Anthropogenic Stress (FORAST) investigators.

\begin{tabular}{ll}
\hline Category & Disturbance history \\
\hline 0 & Unknown \\
1 & Virgin, undisturbed \\
2 & Pre-1900 \\
3 & $1901-1930$ \\
4 & $1931-1971$ \\
5 & $1972-1981$ \\
\hline
\end{tabular}

disturbance regimes. Site information and sampling protocol were reviewed for each chronology using documents from FORAST archived at Carbon Dioxide Information Analysis Center. FORAST investigators selected sites that contained canopy dominant or codominant trees of at least 50 years of age that did not have substantial visual evidence of sitespecific disturbance during that 50-year period (McLaughlin et al. 1988). Two 4-mm cores were extracted at $1.4 \mathrm{~m} \mathrm{DBH}$ on opposite sides of each tree (sensu Phipps 1985). FORAST investigators provided estimates of the stand disturbance history using a temporal rank of the most recent disturbance event (Table 1). This rank was supplemented with a more detailed stand history during the course of the FORAST project. Cores were measured to the nearest $0.05 \mathrm{~mm}$, crossdated, and verified using COFECHA (Holmes 1983). As FORAST focused on growth rates during a 50-year period, measurements from many chronologies did not include pre1930 ring-width data.

The FORAST project also measured stand attributes from a point within $3 \mathrm{~m}$ of each sampled tree to characterize the current forest environment. Prisms with a basal area factor (BAF) of $2.5 \mathrm{~m}^{2} \cdot \mathrm{ha}^{-1}$ were used to estimate basal area from counts of live and total trees. The DBH $(\mathrm{cm})$ of each tree counted by the prism was also recorded to estimate stand density, $D$ (trees $\cdot$ ha $\left.^{-1}\right)$ :

$$
D=\sum_{i}^{n}\left(\mathrm{BAF} \times k^{-1} \times \mathrm{DBH}^{-2}\right)
$$

where $k$ is a conversion factor equal to $7.854 \times 10^{-5} \mathrm{~m}^{2} \cdot \mathrm{cm}^{-2}$ and $n$ is the total number of trees counted at a point (McLaughlin et al. 1988).

FORAST data were imported into MATLAB $^{\circledR} 6.5 .1$ release 13 (Mathworks 2003), and individual cores were queried according to species and site. Because ring widths are typically heteroscedastic, as the variance of ring widths generally increases with their mean (Cook et al. 1990), all width measurements were transformed prior to time-series modeling and intervention detection. The optimal power for the transformation was determined using a regression of $\log _{10}$ ring widths against the $\log _{10}$ of their first differences. The optimal power, $p$, was defined as

$$
\text { [2] } p=1-m
$$

where $m$ is the slope of the regression line (Emerson and Stoto 1983). For $p<0.05$, a $\log _{10}$ transformation was applied, and for $p=1$ no transformation was applied.

Time-series modeling and intervention detection were conducted using FreeFore ${ }^{\circledR}$ version 0.1.20 (Automatic Forecasting
Systems 2004; Reilly 1984). ARIMA models were automatically generated for each tree-ring series following

$$
\text { [3] } \phi(B) \nabla^{d} z_{t}=\theta(B) a_{t}
$$

where $\phi(B)$ is the AR operator with the backward-shift operator $B$, defined as $B z_{t}=z_{t-1}, \nabla^{d}$ is a difference operator of order $d, z_{t}$ is the resultant time series, $\theta(B)$ is the movingaverage operator, and $a_{t}$ is a white-noise process of independent and random shocks with zero mean and variance $\sigma_{a}^{2}$ (see Box et al. (1994) for background information on timeseries analysis). The model order for a given $\operatorname{ARIMA~}(p, q$, $d$ ) process was determined using a nonlinear least squares estimation (Box and Jenkins 1970), where $p, q$, and $d$ are the $\mathrm{AR}$, differencing, and moving-average terms. Additive pulse, step, and trend interventions were then identified sequentially with a $99 \%$ confidence level in accordance with the procedures outlined by McLaughlin et al. (1987) and Downing and McLaughlin (1990). Step and trend interventions were defined as a minimum of five successive growth increments. As step interventions represent the first integral of a pulse intervention, likewise changes in trend were identified by taking the second integral of a pulse intervention (D.P. Reilly, personal communication, 2004). Following intervention detection, FreeFore verified all interventions by using intervention analysis (Box and Tiao 1975). Additionally, the modeling process was reversed within FreeFore by first applying intervention detection and then automatically generating the suitable ARIMA model. A final comparison was made between the two approaches yielding the "best model" for each core.

\section{Results}

FORAST chronologies of eastern hemlock (Tsuga canadensis (L.) Carrière), white pine (Pinus strobus L.), and American beech (Fagus grandifolia Ehrh.) were selected from sites in New Hampshire, Pennsylvania, and Virginia, respectively (Table 2). As many as 32 cores were available for each of these chronologies. According to the disturbance history rank, the $T$. canadensis and $P$. strobus chronologies were both estimated to have experienced a forest disturbance during the mid-20th century, while the $F$. grandifolia chronology was thought to have been last disturbed before the 20th century. The mean diameter of the sampled trees was greatest for the $F$. grandifolia site, which also had the lowest proximal stand density, while the proximal stand basal area was greatest for the $P$. strobus site (Table 2).

Of all the series across chronologies, $72 \%$ were estimated as AR (1) models; however, occasionally higher order AR and differenced models were estimated (Table 3 ). Figures 1 and 2 present the transformed ring widths and detected interventions for two representative cores. Core H7E131 was power transformed $(p=0.62)$ and contained a change in level in 1945 of $1.08 \mathrm{~mm}$ transformed followed by a change in trend in 1959 of $-0.06 \mathrm{~mm}$ transformed (Fig. 1). Core F6C122 was $\log _{10}$ transformed $(p=-0.33)$ and contained pulse outliers in 1945,1948 , and 1958 of magnitudes $0.23,0.36$, and $0.40 \mathrm{~mm}$ transformed, respectively. These pulse outliers were followed in 1965 by a change in level of $-0.49 \mathrm{~mm}$ transformed (Fig. 2).

Figure 3 summarizes detected interventions by type for each core within the three chronologies analyzed in this 
Table 2. Descriptive information on sample site and surrounding forest conditions for three chronologies (Tsuga canadensis, Pinus strobus, and Fagus grandifolia) from the Forest Responses to Anthropogenic Stress (FORAST) project.

\begin{tabular}{llll}
\hline Chronology & T. canadensis & $P$. strobus & F. grandifolia \\
\hline Site name & Hubbard Brook & Rockview & Camp Potomac \\
Elevation $(\mathrm{m})$ & 520 & 320 & 92 \\
State $($ abbrev.) & N.H. & Penn. & Va. \\
Latitude $\left({ }^{\circ} \mathrm{N}\right)$ & 43.933 & 40.850 & 39.233 \\
Longitude $\left({ }^{\circ} \mathrm{W}\right)$ & 71.733 & 77.816 & 76.250 \\
No. of trees sampled & 15 & 14 & 16 \\
No. of cores extracted & 30 & 28 & 32 \\
Estimated disturbance category & 4 & 4 & 2 \\
No. of basal area samples & 15 & 14 & 15 \\
Sampled tree DBH $(\mathrm{cm}) \pm \mathrm{SE}$ & $35.3 \pm 2.0$ & $44.7 \pm 2.6$ & $47.9 \pm 1.9$ \\
Stand basal area $\left(\mathrm{m}^{2} \cdot \mathrm{ha}\right.$ & -1 \\
Stand density $\left(\right.$ trees $\left.^{-1} \cdot \mathrm{ha}^{-1}\right) \pm \mathrm{SE}$ & $24.8 \pm 2.3$ & $30.9 \pm 2.1$ & $26.2 \pm 1.6$ \\
\hline
\end{tabular}

Table 3. Counts of autoregressive integrated moving-average (ARIMA) model order determined for three Forest Responses to Anthropogenic Stress (FORAST) chronologies (Tsuga canadensis, Pinus strobus, and Fagus grandifolia).

\begin{tabular}{lccc}
\hline Model order $^{a}$ & T. canadensis & $P$. strobus & $F$. grandifolia \\
\hline$(0,0,0)$ & 4 & 4 & 5 \\
$(1,0,0)$ & 21 & 22 & 22 \\
$(2,0,0)$ & 0 & 1 & 3 \\
$(3,0,0)$ & 4 & 1 & 1 \\
$(1,1,0)$ & 1 & 0 & 0 \\
$(0,1,0)$ & 0 & 0 & 1 \\
\hline
\end{tabular}

${ }^{a}$ From left to right, the model order expresses the autoregressive, difference, and moving-average terms.

study. The $T$. canadensis chronology exhibited 17 positive step interventions between 1938 and 1942 and 13 negative step interventions between 1956 and 1963. Furthermore, 71\% of the cores that showed a positive step intervention between 1938 and 1942 were followed by negative step intervention between 1956 and 1963. The P. strobus chronology contained 15 positive step, 14 positive pulse, and 4 positive trend interventions between 1944 and 1949; 11 negative step interventions were identified between 1962 and 1971. Similarly to the $T$. canadensis chronology, $60 \%$ of the cores that initially showed a positive step intervention subsequently showed a negative step intervention. The $F$. grandifolia chronology exhibited 10 positive step, 6 positive pulse, and 1 positive trend interventions during the years 1928 to 1934 followed by 16 negative step and 4 negative trend interventions from 1951 to 1971. Again, 60\% of the cores that initially showed a positive step intervention subsequently showed a negative step intervention.

\section{Discussion}

\section{Forest history reconstruction of three FORAST chronologies}

The forest surrounding the sampled $T$. canadensis trees possessed a lower basal area and a greatly reduced density than that reported in a study examining the entire Hubbard Brook Experimental Forest and an adjacent undisturbed for- est $\left(31.8 \mathrm{~m}^{2} \cdot \mathrm{ha}^{-1}\right.$ and $>2000 \mathrm{stems} \cdot \mathrm{ha}^{-1}$ for both sites $)$ when compared with all trees $>2 \mathrm{~cm}$ DBH (Schwarz et al. 2001). The forest surrounding the $P$. strobus trees also displayed a reduced basal area and density when compared with regional old-growth forest estimates from Morey (1936) of 37.4 to $63.9 \mathrm{~m}^{2} \cdot \mathrm{ha}^{-1}$ and 1048 to 1562 trees $\cdot \mathrm{ha}^{-1}$ for all trees $>2.54 \mathrm{~cm}$ DBH. Similarly, the forest surrounding the $F$. grandifolia trees also showed reduced basal area and density than that of a remnant forest in the Virginia piedmont (Druckenbrod and Shugart 2004) with a mean basal area of $43.1 \mathrm{~m}^{2} \cdot \mathrm{ha}^{-1}$ and density of 1749 trees $\cdot \mathrm{ha}^{-1}$ for all trees $>1.37 \mathrm{~m}$ in height. The basal area estimates for these forests suggest that they are successional forests that have not yet reached old-growth conditions for their respective regions; however, the greatly reduced stand density values are less than expected for these forests. As shown by eq. 2, the estimated density contributed by each tree within the angle of a prism varies inversely with the square of its diameter. Thus, if smaller trees were not accurately recorded using the prism method, then the estimates of point densities would be reduced more than the estimates of basal areas. Also, sample point locations were systematically placed adjacent to sample trees (within $3 \mathrm{~m}$ ), resulting in a possible bias if smaller trees were consistently segregated from sample trees. Alternatively, it may be possible that all three forests surrounding these sample trees exhibit reduced densities and that these densities could be an artifact of prior disturbance.

Although hurricanes are a relatively infrequent disturbance on the northern hardwood-conifer forests of New England, they can have intense local impacts on stand structure (Bormann and Likens 1979; Merrens and Peart 1992). In 1938, the most recent major hurricane resulted in a localized forest disturbance within the Hubbard Brook Experimental Forest (Peart et al. 1992). According to FORAST site history description, the $T$. canadensis chronology was sampled within an area severely impacted by both the hurricane and possible salvage logging the year after the hurricane (Peart et al. 1992). Aerial photographs of this area, designated as area A by Peart et al. (1992), showed 18\% cover in 1942 and 72\% open conditions; however, $75 \%$ of this area had returned to high canopy cover by 1978 with only $9 \%$ open conditions. The interventions identified in Fig. 3A reflect the impact of the hurricane disturbance with subsequent positive step out- 
Fig. 1. (A) Ring widths of a hemlock (Tsuga canadensis) core sampled from the Hubbard Brook Experimental Forest, New Hampshire (ID\#: H7E131). (B) Power-transformed ring widths displaying a shift in level detected in 1945 and a change in trend in 1959. Interventions are shown with a broken line.
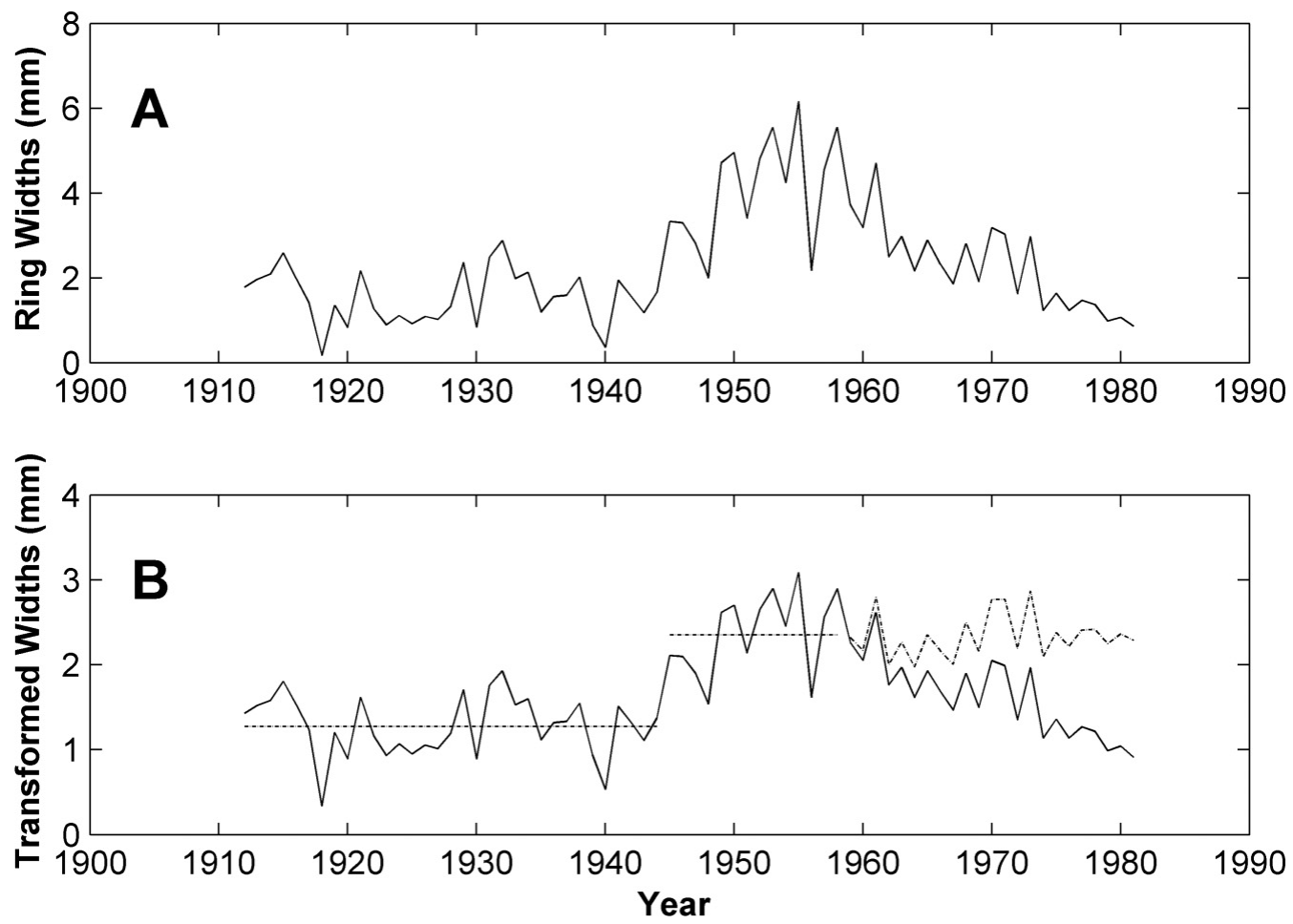

Fig. 2. (A) Ring widths of a white pine (Pinus strobus) core sampled near the Rockview State Correctional Institution, Pennsylvania (ID\#: F6C122). (B) $\log _{10}$-transformed ring widths displaying pulse interventions in 1945, 1948, and 1958 and a shift in level in 1965. Interventions are shown with a broken line.
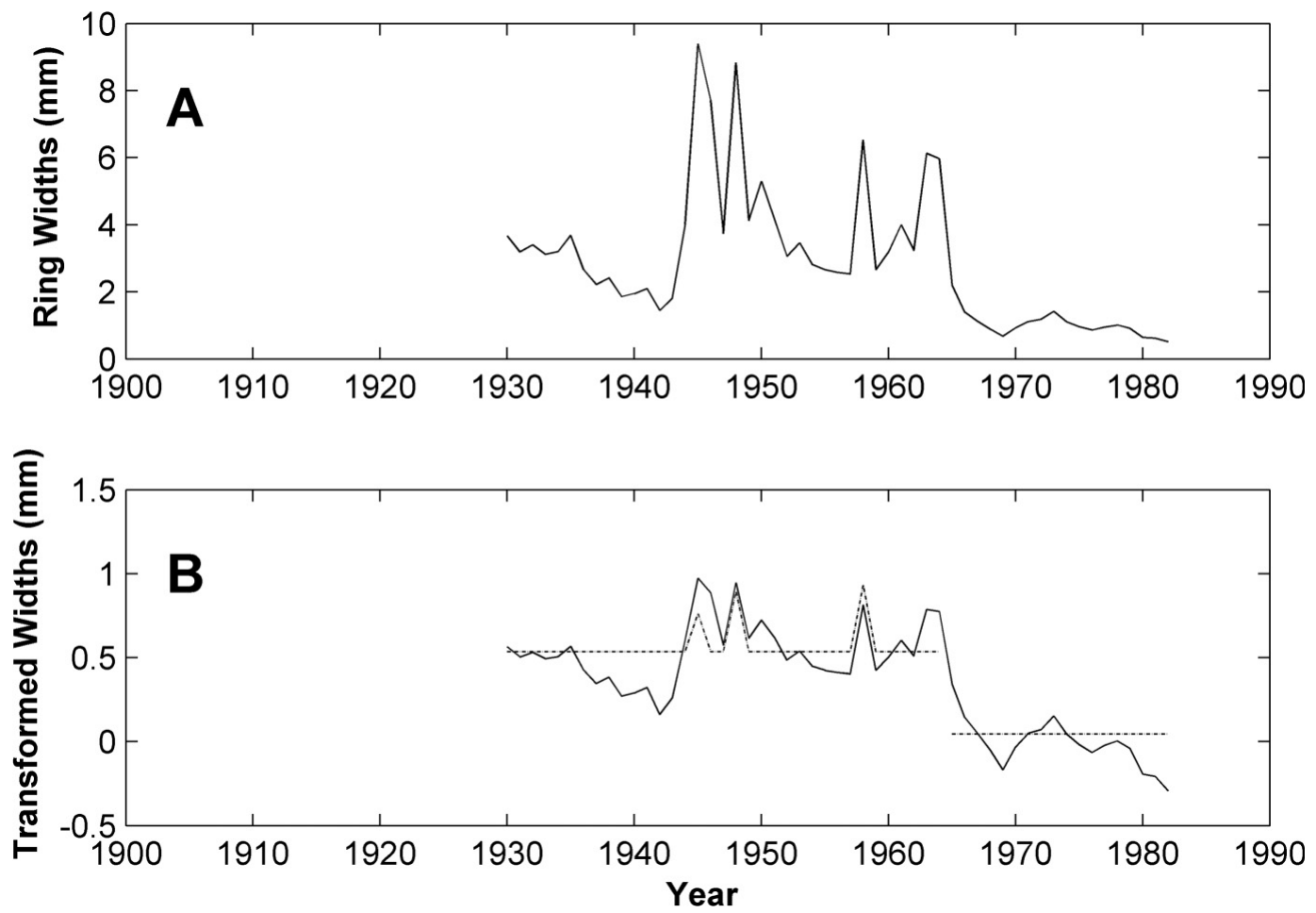

liers, although the later step outliers in 1941 and 1942 could be an indication of salvage logging that occurred in the area. This interpretation agrees with Merrens and Peart (1992), who observed radial-growth increases in several other canopy species concurrently. Additionally, the negative step interventions indicated by the chronology circa 1960 suggest the return to 
Fig. 3. Counts of pulse, step, and trend outliers identified using time-series analysis with intervention detection for three chronologies of tree rings: (A) hemlock (Tsuga canadensis) from the Hubbard Brook Experimental Forest, New Hampshire; (B) white pine (Pinus strobus) near the Rockview State Correctional Institution, Pennsylvania; and (C) American beech (Fagus grandifolia) from Camp Potomac Woods, Virginia. Step interventions are depicted in black, pulse interventions in gray, and trend interventions in white. The bounds of the sample depth are shown with a broken line.
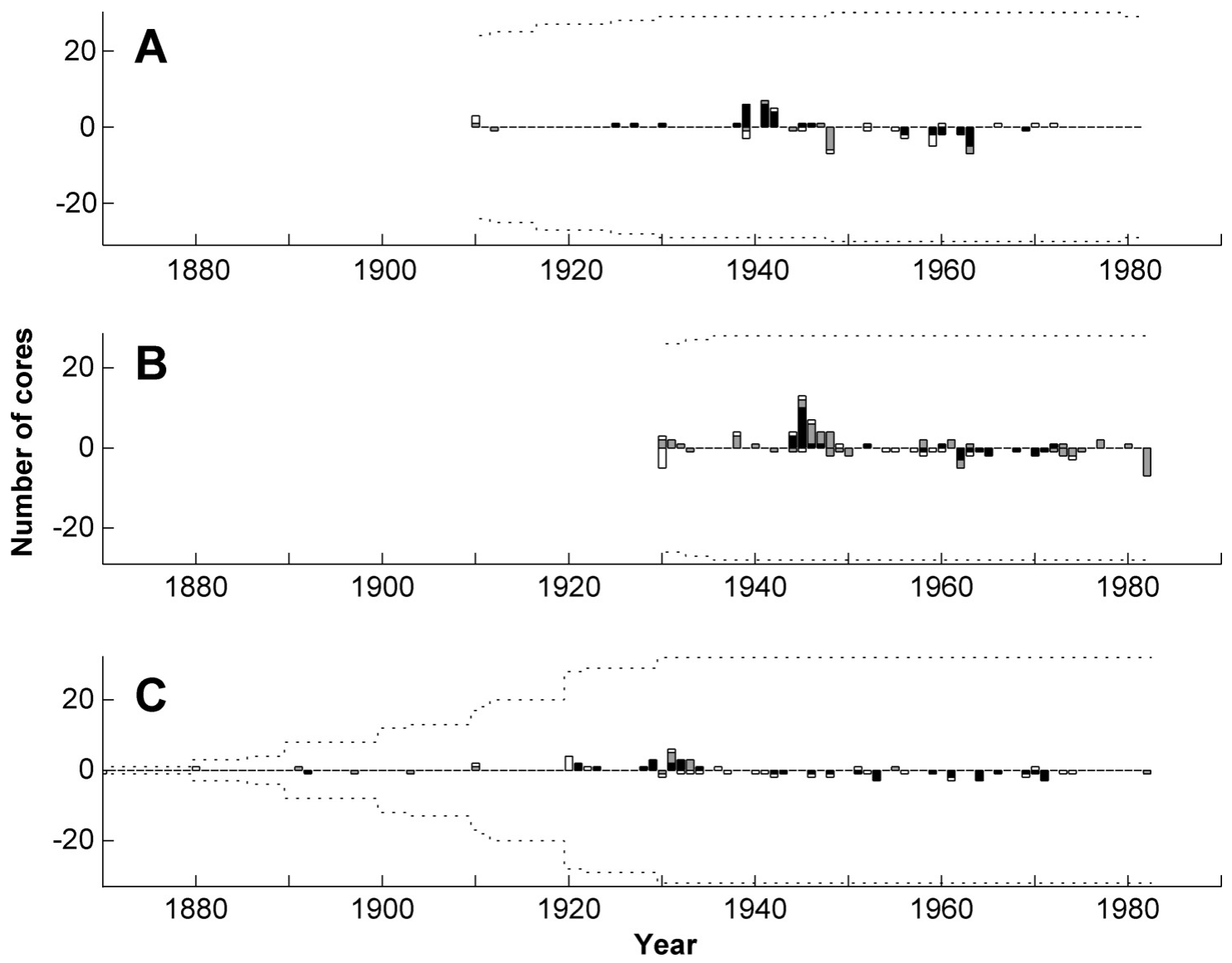

closed-canopy conditions that were observed in the 1978 aerial photographs. These conditions could also lead to a return to reduced growth rates for trees that are not canopy dominants.

The $P$. strobus chronology was sampled on land maintained by the Rockview State Correctional Institution for the Commonwealth of Pennsylvania Department of Corrections. The FORAST site history description states that these forests were actively managed for timber production by inmates who used an onsite sawmill. Timber harvesting records, which were available only since the mid-1950s, showed selective harvesting in 1956-1957 and in 1970 in the vicinity of the dendroecological sampling; however, the sampling avoided areas with indications of recent logging. The grouping of positive step, pulse, and trend interventions in the 1940 s suggests that the stand surrounding the $P$. strobus chronologies may not have been disturbed by these recent thinnings, but, instead, that the stand may have been impacted by an earlier, unrecorded harvest in the mid-1940s (Fig. 3B). The presence of negative step interventions subsequently in the 1960s could suggest a similar crown-closure response as suggested in the T. canadensis chronology; however, no independent information is available to support this transition.

Camp Potomac Woods, the location of the F. grandifolia chronology, is owned by the Girl Scout Council of the Na- tion's Capital (GSCNC). A caretaker, who has been employed by the GSCNC for 46 years, recalls that the forests around the camp were logged prior to 1949 (A. Quisenberry, personal communication, 2004). The positive step, pulse, and trend interventions from 1928 to 1934 support this interpretation of the forest history (Fig. 3C). Again, the subsequent negative interventions suggest a return to closed-canopy conditions by 1971 .

\section{Application of time-series analysis with intervention detection to dendroecology}

Alternative statistical approaches to identifying interventions in time series have also been developed. For example, the field of climatology has recognized that inhomogeneities may occur in climate time series. These step shifts are typically referred to as discontinuities or changepoints, and several methods have been developed to address them; however, the majority require a reference time series and none of these methods have been tested on series with high autocorrelation (Lund and Reeves 2002; Ducré-Robitaille et al. 2003).

When a time-series analysis is used, the autocorrelation typically present in tree-ring time series can be accounted for by specific, empirical models generated for each core. Time-series analysis with intervention detection also reduces 
the possibility of introducing spurious events (i.e., false positives analogous to type I error), which may arise when generating running means from time series (Cole 1957; Druckenbrod and Shugart 2004). Rubino and McCarthy (2004) recognize that decadal intervals of tree-ring data are often not normally distributed; they suggest employing the median instead of the mean in radial-averaging methods. While their adjustment moves toward statistical considerations in reconstructing forest history, it does not fully consider the relationships between sequential increments in tree-ring data.

The radial-growth averaging, boundary-line method of Black and Abrams (2003) requires sufficient data to adequately represent a population of radial-growth measurements for each species across a variety of site and stand conditions. In contrast, time-series analysis with intervention detection generates an empirical model specific to each time series analyzed. Therefore, this approach requires no assumptions concerning all possible growth rates for a particular species or prior conditions affecting a particular tree. Time-series analysis with intervention detection also follows a conservative approach by allowing for the detection of all possible disturbance events recorded in the changing growth rates of trees. Running means typically use a decadal interval in an attempt to minimize shorter and longer term climate influence on tree growth. Time-series analysis with intervention detection requires no assumption as to the periodicity of a climate influence on tree growth. Rather, this method identifies all exogenous interventions on tree growth and enables a comparison with any possible external influence on tree growth. Similiar to radial-growth averaging, time-series analysis with intervention detection is likely limited to detecting only disturbance events that occur after the establishment of a tree. Disturbances that enable tree establishment in gaps with higher initial growth rates would presumably require inference from any subsequent decline in growth after a return to shaded canopy conditions. Time-series analysis with intervention detection does have the potential to account for gradual growth responses to a disturbance such as those reported by Jones and Thomas (2004). These patterns could be modeled either with specific transfer functions (see Box and Tiao 1975) or with the recognition of a particular sequence of pulse interventions prior to a level shift.

Intervention detection and intervention analysis are being applied more frequently to the interpretation and reconstruction of environmental dynamics from tree rings. These methods have been used with respect to questions about growth decline relating to air pollution (Cook and Innes 1989), with reconstructions of the Pacific decadal oscillation from tree rings (Gedalof and Smith 2001), and with reconstructions of growth rates prior to tree mortality (Pedersen 1998). However, apparently only two dendroecological disturbance studies utilized these methods since McLaughlin et al. (1987). Mäkinen (1997) used intervention analysis to investigate the impact of known, prior stand-thinning treatments on tree growth. Also, Segura et al. (1995) used intervention analysis to examine the influence of tephra deposition on tree growth.

Intervention detection has potentially greater application for dendroecology than intervention analysis because of its ability to detect unknown prior disturbance events. Intervention detection may also have applications in the identification of specific disturbance regimes on tree growth by focusing on the frequency and sign of different types of outliers. For example, Lafon and Speer (2002) report a dual signal in the running means of tree-ring widths following an ice storm. Heavily damaged trees exhibited reduced growth, while less damaged trees appeared to exhibit a release from competition for resources from surrounding trees. These signals could possibly be characterized uniquely by the presence of positive and negative step interventions. If so, intervention detection could provide inference not only as to the presence of a disturbance event, but also possibly as to the type of event.

In conclusion, time-series analysis with intervention detection provides a statistical approach to the reconstruction of prior disturbance events affecting the radial-growth rate recorded in tree rings. As shown by these three FORAST chronologies, pulse, step, and trend interventions coincide with known or likely prior disturbance events within each of these forests. While time-series analysis has a rich history in its application to dendroclimatology, these results indicate that there is great potential for the application of these methods to dendroecology as well.

\section{Acknowledgements}

The author gratefully acknowledges assistance provided from the following individuals: E.R. Cook with data transformation and time series modeling, S.B. McLaughlin with the FORAST database and documentation, D.P. Reilly at Automatic Forecasting Systems with the application of intervention detection within FreeFore ${ }^{\circledR}$, and T.J. Blasing with helpful comments on the manuscript. The author also acknowledges the following FORAST investigators who sampled the stands investigated in this paper: D. Davis, A. Johnson, R. Long, L. Puckett, R. Phipps, T. Siccama, W. Smith, and J. Whiton. This research was performed at Oak Ridge National Laboratory (ORNL). ORNL is managed by UT-Battelle, LLC, for the U.S. Department of Energy under contract DEAC05-00OR22725.

\section{References}

Abrams, M.D., Copenheaver, C.A., Terazawa, K., Umeki, K., Takiya, M., and Nobuhiro, A. 1999. A 370-year dendroecological history of an old growth Abies-Acer-Quercus forest in Hokkaido, northern Japan. Can. J. For. Res. 29: 1891-1899.

Automatic Forecasting Systems. 2004. FreeFore. Version 0.1.20 [computer program]. Automatic Forecasting Systems. Hatboro, Pa.

Black, B.A., and Abrams, M.D. 2003. Use of boundary-line growth patterns as a basis for dendroecological release criteria. Ecol. Appl. 13: 1733-1749.

Bormann, E.H., and Likens, G.E. 1979. Pattern and process in a forested ecosystem. Springer-Verlag, New York.

Box, G.E.P., and Jenkins, G.M. 1970. Time series analysis: forecasting and control. Holden-Day, San Francisco, Calif.

Box, G.E.P., and Tiao, G.C. 1975. Intervention analysis with applications to economic and environmental problems. J. Am. Stat. Assoc. 70: 70-79.

Box, G.E.P., Jenkins, G.M., and Reinsel, G.C. 1994. Time series analysis: forecasting and control. 3rd ed. Prentice Hall, Englewood Cliffs, N.J. 
Chang, I. 1982. Outliers in time series. Ph.D. thesis, Department of Statistics, University of Wisconsin-Madison, Madison, Wis.

Chang, I., Tiao, G.C., and Chen, C. 1988. Estimation of time series parameters in the presence of outliers. Technometrics, 30: 193204.

Cole, L.C. 1957. Biological clock in the unicorn. Science (Washington, D.C.), 125: 874-876.

Contributors of the International Tree-Ring Data Bank. 2004. IGBP PAGES / World Data Center for Paleoclimatology [online]. NOAA/ NGDC Paleoclimatology Program, Boulder, Colorado. Available from http://www.ngdc.noaa.gov/paleo/treering.html [cited March 2004].

Cook, E.R. 1985. A time series analysis approach to tree ring standardization. Ph.D. thesis, Department of Geosciences, University of Arizona, Tucson, Ariz.

Cook, E.R., and Innes, J.L. 1989. Tree-ring analysis as an aid to evaluating the effects of air pollution on tree growth. In Biologic markers of air-pollution stress and damage in forests. Edited by Committee on Biologic Markers of Air-Pollution Damage in Trees, National Research Council, Washington, D.C. pp. 157168.

Cook, E.R., Briffa, K., Shiyatov, S., and Mazepa, V. 1990. Treering standardization and growth-trend estimation. In Methods of dendrochronology. Edited by E.R. Cook and L.A. Kairiukstis. International Institute for Applied Systems Analysis, Netherlands. pp. 104-123.

Downing, D.J., and McLaughlin, S.B. 1990. Detecting shifts in radial growth by use of intervention detection. In Methods of dendrochronology. Edited by E.R. Cook and L.A. Kairiukstis. International Institute for Applied Systems Analysis, Netherlands. pp. 258-270.

Druckenbrod, D.L., and Shugart, H.H. 2004. Forest history of James Madison's Montpelier plantation. J. Torr. Bot. Soc. 131: 204-219.

Ducré-Robitaille, J., Vincent, L.A., and Boulet, G. 2003. Comparison of techniques for detection of discontinuities in temperature series. Int. J. Climatology, 23: 1087-1101.

Emerson, J.D., and Stoto, M.A. 1983. Transforming data. In Understanding robust and exploratory data analysis. Edited by D.C. Hoaglin, F. Mosteller, and J.W. Tukey. John Wiley \& Sons, New York.

Fox, A.J. 1972. Outliers in time series. J. R. Stat. Soc. B, 34: 350363.

Frelich, L.E. 2002. Forest dynamics and disturbance regimes: studies from temperate evergreen-deciduous forests. Cambridge University Press, New York.

Fritts, H.C. 1976. Tree rings and climate. Academic Press, New York.

Gedalof, Z., and Smith, D.J. 2001. Interdecadal climate variability and regime-scale shifts in Pacific North America. Geophys. Res. Lett. 28: 1515-1518.

Guiot, J. 1986. ARMA techniques for modelling tree-ring response to climate and for reconstructing variations of paleoclimates. Ecol. Model. 33: 149-171.

Henry, J.D., and Swan, J.M.A. 1974. Reconstructing forest history from live and dead plant material — an approach to the study of forest succession in southwest New Hampshire. Ecology, 55: 772-783.

Holmes, R.L. 1983. Computer-assisted quality control in tree-ring dating and measurement. Tree-Ring Bull. 44: 69-75.

Jones, T.A., and Thomas, S.C. 2004. The time course of diameter increment responses to selection harvests in Acer saccharum. Can. J. For. Res. 34: 1525-1533.
Lafon, C.W., and Speer, J.H. 2002. Using dendrochronology to identify major ice storm events in oak forests of southwestern Virginia. Clim. Res. 20: 41-54.

Lorimer, C.G., and Frelich, L.E. 1989. A methodology for estimating canopy disturbance frequency and intensity in dense temperate forests. Can. J. For. Res. 19: 651-663.

Lund, R., and Reeves, J. 2002. Detection of undocumented changepoints: a revision of the two-phase regression model. J. Clim. 15: $2547-2554$

Mäkinen, H. 1997. Reducing the effects of disturbance on tree-ring data using intervention detection. Scand. J. For. Res. 12: 351355.

Mathworks. 2003. MATLAB 6.5.1 release 13 [computer program]. The Mathworks, Inc., Natick, Mass.

McLaughlin, S.B., Downing, D.J., Blasing, T.J., Jackson, B.L., Pack, D.J., Duvick, D.N., Mann, L.K., and Doyle, T.W. 1986. FORAST database [online]. Carbon Dioxide Information Analysis Center. Available from http://cdiac.ornl.gov/ndps/db1005.html [cited March 2004].

McLaughlin, S.B., Downing, D.J., Blasing, T.J., Cook, E.R., and Adams, H.S. 1987. An analysis of climate and competition as contributors to decline of red spruce in high elevation Appalachian forests of the Eastern United States. Oecologia, 72: 487501.

McLaughlin, S.B., Downing, D.J., Blasing, T.J., Jackson, B.L., Pack, D.J., Duvick, D.N., Mann, L.K., and Doyle, T.W. 1988. FORAST database documentation [computer program]. Environmental Protection Agency [EPAORD EPA/600/3 87/029A], Corvallis, Ore.

Meko, D.M. 1981. Application of Box-Jenkins methods of time series analysis to the reconstruction of drought from tree rings. Ph.D. thesis, University of Arizona, Tucson, Ariz.

Merrens, E.J., and Peart, D.R. 1992. Effects of hurricane damage on individual growth and stand structure in a hardwood forest in New Hampshire, USA. J. Ecol. 80: 787-795.

Monserud, R.A. 1986. Time-series analyses of tree-ring chronologies. For. Sci. 32: 349-372.

Morey, H.F. 1936. A comparison of two virgin forests in northwestern Pennsylvania. Ecology, 17: 43-55.

Nowacki, G.J., and Abrams, M.D. 1997. Radial-growth averaging criteria for reconstructing disturbance histories from presettlement-origin oaks. Ecol. Monogr. 67: 225-249.

Oliver, C.D., and Stephens, E.P. 1977. Reconstruction of a mixedspecies forest in central New England. Ecology, 58: 562-572.

Peart, D.R., Cogbill, C.V., and Palmiotto, P.A. 1992. Effects of logging history and hurricane damage on canopy structure in a northern hardwoods forest. Bull. Torrey Bot. Club, 119: 29-38.

Pedersen, B.S. 1998. The role of stress in the mortality of midwestern oaks as indicated by growth prior to death. Ecology, 79: 79-93.

Phipps, R.L. 1985. Collecting, preparing, crossdating, and measuring tree increment cores. U.S. Geol. Surv. Water-Resour. Invest. Rep. 85-4148.

Reilly, D.P. 1984. Smart software for time series data analysis. Am. Statist. 38: 315.

Rentch, J.S., Fajvan, M.A., and Hicks, R.R.J. 2003. Spatial and temporal disturbance characteristics of oak-dominated old-growth stands in the Central Hardwood Forest Region. For. Sci. 49: 778-789.

Rose, M.R. 1983. Time domain characteristics of tree-ring chronologies and eigenvector amplitude series from western North America. University of Arizona, Lab. Tree-Ring Res. Tech. Note 25. 
Rozas, V. 2003. Regeneration patterns, dendroecology, and forestuse history in an old-growth beech-oak lowland forest in Northern Spain. For. Ecol. Manage. 182: 175-194.

Rubino, D.L., and McCarthy, B.C. 2004. Comparative analysis of dendroecological methods used to assess disturbance events. Dendrochronologia, 21: 97-116.

Schwarz, P.A., Fahey, T.J., Martin, C.W., Siccama, T.G., and Bailey, A. 2001. Structure and composition of three northern hardwood-conifer forests with differing disturbance histories. For. Ecol. Manage. 144: 201-212.

Segura, G., Hinckley, T.M., and Brubaker, L.B. 1995. Variations in radial growth of declining old-growth stands of Abies amabilis after tephra deposition from Mount St. Helens. Can. J. For. Res. 25: 1484-1492.

Stephens, E.P. 1956. The uprooting of trees: a forest process. Soil Sci. Soc. Am. Proc. 20: 113-116.

Tsay, R.S. 1988. Outliers, level shifts, and variance changes in time series. J. Forecasting, 7: 1-20.

White, P.S., and Pickett, S.T.A. 1985. Natural disturbance and patch dynamics: an introduction. In The ecology of natural disturbance and patch dynamics. Edited by S.T.A. Pickett and P.S. White. Academic Press, New York. pp. 3-13. 